\title{
Oral Drops, Suspension Dosage Form
}

National Cancer Institute

\section{Source}

National Cancer Institute. Oral Drops, Suspension Dosage Form. NCI Thesaurus. Code C149712.

Liquid, usually multidose preparation consisting of a suspension intended for oral use.

The preparation is administered in small volumes by means of a suitable measuring device such as a dropper, pipette or oral syringe capable of accurate dosing of the suspension. The measured dose may be diluted in water or another suitable liquid before swallowing. 